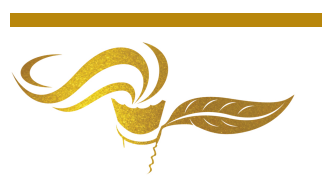

\title{
The impact of the COVID-19 lockdown rules on the socio-psychological condition of the people over 65 in Azerbaijan
}

\author{
Lala Huseynova (student) ${ }^{1}$ and Paul Gibbs (advisor) ${ }^{2}$ \\ 1 Azerbaijan University, Social Work, Azerbaijan \\ 2 Emeritus Professor, Middlesex University, London, UK \\ * Correspondence: Email: p.gibbs@mdx.ac.uk
}

Received 27 November, 2020; Revised 3 February, 2021; Accepted 3 February, 2021

Available online 4 February, 2021 at www.atlas-journal.org, doi: 10.22545/2021/00155

\section{Short Letter}

The new coronavirus (Covid-19) epidemic, was first detected in Azerbaijan in February 2020. This epidemic, in addition to the impact on human health, has had a negative impact across the country for the economy, tourism, social relations and the conditions necessary for human life. International reports show that the group most at risk of the pandemic is the older population. The coronavirus pandemic has disproportionately affected this group, both in terms of hospitalizations and deaths, but also by the consequences of restrictions on social contact resulting in physical de-conditioning and worsened mental health (Briguglio, 2020 [1]) which caused them to be more vulnerable to the other socio-cultural and economic factors.

I contend that the global research response to the COVID-19 pandemic has not been focused on the general needs of older people; rather research has focused on treatment more than prevention or rehabilitation, on hospital care rather than community care, on counting deaths rather than measuring function and on younger people rather than older people (Fraser, 2020 [2], Lithander, 2020 [3]). The consequences of the pandemic not only affect the health of the elderly, but also their psychological, physiological and social status. Thus, isolationist speeches against them, such as self-loathing, death phobia, loss of contact with peers, make life difficult for them. They thought that if they contracted the virus, their lives would end, their beliefs about overcoming the disease would weaken, and their failure to continue their social life as usual would lead to depression. Indeed, recently Soto-Perez-de-Celis (2020 [4]) has claimed that there are negative social media messages about COVID-19 and aging, often characterizing older adults as helpless and expendable individuals. Kluge (2020 [5]), WHO Regional Director for Europe, addressing journalists at a virtual press briefing said "I am reminding governments and authorities that all communities must be supported to deliver interventions to ensure older people have what they need. All 
Lala Huseynova and Paul Gibbs

The impact of the COVID-19 lockdown rules on the socio-psychological condition of the people over 65 in Azerbaijan

older people should be treated with respect and dignity during these times. Remember, we leave no one behind".

Azerbaijan: Azerbaijan has enacted very restrictive for the whole urban population and the list of quarantine rules that apply specifically to people over 65 include the following:

- People over the age of 65 should not be allowed to leave their homes. To provide social services to this category of single people in accordance with the legislation.

- Prohibit access to vehicles without medical masks, catering facilities, shopping centers.

- Restrict labor activities during the quarantine period for the health of the elderly.

When dealing with pandemic-related problems, people over the age of 65 should be aware of the challenges posed by physical and social distance. In the first place, during the pandemic, in addition to the COVID-19 virus, the elderly should be interested in other necessary needs and problems. This is one of the steps to be taken to regulate the psychological state of the elderly during the period of isolation. When an elderly person stays in an isolated home, they may not take sufficient care about their diet or the level of fluids they need to drink, which might aggravate underlying health problems and lead to heart failure or other problems. The consequences of the most important psychological effect of isolation are loneliness and carelessness. The thought that they can spread the infection among themselves and their loved ones, and that this time is getting longer, leads to a kind of exhaustion and psychological trauma in the elderly. This pattern of everyday physical distancing worldwide, particularly for adults aged $65+$. Such distancing can evoke subjective feelings of loneliness among older adults, but how this pandemic has influenced that loneliness is not yet known. Seifert and Hassler (2020 [6]) concluded that this loneliness was directly or indirectly related to "(a) limiting social contact opportunities; (b) making older individuals reflect on their social/support networks, potentially evaluating them as frail; (c) labelling older adults as "at risk," possibly causing them to be shunned; and (d) making older individuals feel lonely because society considered them old and frail and, therefore, lonely".

Older people think psychologically that it is more difficult for an elderly person in an urban area to protect themselves from the COVID-19 pandemic. If an elderly person in the city protects himself from the Covid-19 pandemic, it means that he should not leave his place of residence, always use disinfectants, pay attention to those who come and go, avoid contact with relatives as much as possible. This has a psychological effect on people over 65 years of age. It is psychologically easier for people over the age of 65 living in a district or village to protect themselves from the Covid-19 pandemic than in a city. While elderly people living in the city are forced to stay at home due to quarantine rules, people over the age of 65 living in the district or village can go outside and get fresh air, because there is not much crowding in the district and village.

In Azerbaijan social workers provide service to vulnerable older people a their homes. During the special quarantine period, citizens over the age of 65 and currently living alone are provided with social services at home. Social services at home are provided by local branches of the Agency for Social Services and DOST centers under the Ministry of Labor and Social Protection of Population of the Republic of Azerbaijan. This support for older people, their families and their caregivers is an essential part of the country's comprehensive response to the pandemic. Further it has been assumed centrally, albeit for compassionate reasons, that older people need safe access to nutritious food, basic supplies, money, medicine to support their physical health, and social care, but they are unable to provide this for themselves. This service did little to help a most pressing problem, that of isolation and of enhancing the self-efficacy of older people. For example, during the pandemic services were provided for older people which are included in the list below, but social workers do not enter the house to engage in social interaction. Moreover, such a service, where the people are able, removed the dignity and confidence of the person in acting within their own competency: it often reduced independent agents to one of dependence and learned helplessness. These services include:

- Purchase of medicines 
- Purchase of necessary food, industrial and household goods

- Take to the doctor, etc.

- Social services at home are suspended in the following cases:

1. When another person moves to the citizen's house

2. When lonely elderly people are placed in state social service institutions

3. When a person in need of social services dies

This support for older people, their families and their caregivers has been seen an essential part of the country's comprehensive response to the pandemic but there is growing if anecdotal, evidence important that in providing services there is no marginalization of older people. Further research is needed to substantiate this premise but this papers suggests that the response derived from such study ought to be transdisciplinary, focusing on the wide impacts of the pandemic not just the protection of the elderly from contracting the virus but also on ensuring that their way of life is supported, that they retain their dignity and that remaining safe embraces their mental as well s physical condition.

\section{A Transdisciplinary Response:}

Pandemics are likely to become more frequent given the increasing interconnectedness of the world and our closer proximity to wildlife due to human encroachment. To be prepared requires transdisciplinary preparation: Lawrence has argued that the coronavirus pandemic "should be considered as a transdisciplinary societal challenge that requires coordinated systemic thinking and actions in the context of uncertainty". Indeed the health, economic and social impacts of Covid-19 are complex, emergent and unpredictable and a transdisciplinary approach might have advantages in dealing with the identified problems above. Transdisciplinarity (transdisciplinary research) is understood here as comprising a commitment to the framing of the question of over 65 care by integrating different domains and disciplines of knowledge, even when this means working across different theoretical perspectives and methodological practices. This brings a focus on real-world problems, where context and complexity are recognised and confronted as part of the methodology.

Transdisciplinarity however, requires systems thinking. Systems thinking is a set of skills to recognize parts of systems and their interconnection, identify and understand cause-effect feedback loops, and understand system structure, dynamic behavior, and systems at different scales - in other words, systems thinking is the ability of seeing both the forest and the trees. We see that the potential of systems thinking and transdisciplinary science has not yet been utilized in the attempt to overcome the COVID 19 crisis. Lawrence concludes "that transdisciplinary contributions can make a crucial contribution in defining the contingent factors that enable or inhibit decision making to deal with societal challenges" (2020a: 198).

This is not easy. A recent report by the OECD Global Science Forum (2020) found that despite increasing interest at the policy level, there are significant barriers to conducting rigorous transdisciplinary research. In this report they offer a number of case studies that address complex public health issues or crises. The report suggests policy makers and other actors with a shared interest in how science can effectively support solutions for complex societal challenges. These include actions from Governments, research agencies, research institutions and international bodies to design and implementing effective policy initiatives. They advocate mutual learning, collaboration, and exchange are required at the policy level as well as at the practitioner level. As Lawrence has suggested, that important as discipline-based expertise is needed in dealing with Covid, this alone cannot "provide a comprehensive understanding necessary for effective responses to its multiple impacts within and beyond the public health sector" (2020a: 1). He goes further to support the OECD report's recommendation suggesting that Covid should be considered as an "emergent, complex, contextual, and systemic societal challenge that requires concerted actions involving not only disciplinary and professional expertise but also other types of knowledge and know-how" (ibid).

Such collaboration within the stakeholders of Azerbaijan's policy and implementation services would create a more cohesive and comprehensive approach to the problems expressed by the older population. 
Lala Huseynova and Paul Gibbs

The impact of the COVID-19 lockdown rules on the socio-psychological condition of the people over 65 in

Azerbaijan

These problems are not those where one agency working from within one type of portfolio or supportive agency can solve. It needs a clear and collaborative approach which addresses the problems as presented by those who suffer. Solutions will come from working with those affected, understanding their concerns and seeing how the resources available can be brought to together to solve these pressing problems. The challenge is huge and it is one that Azerbaijan, in dealing with and responding to the post-Covid situation, shares with the rest of the world.

\section{References}

[1] Briguglio M, Giorgino R, Dell'Osso Bet al.( 2020). Consequences for the elderly after COVID-19 isolation: FEAR (frail elderlyamid restrictions). Front Psychol 2020; 11: 565052.

[2] Fraser S, Lagacé M, Bongué Bet al. (2020). Ageism and COVID-19: what does our society's response say about us? Age Ageing, 49: 692-5.

[3] Lithander FE, Neumann S, Tenison Eet al. (2020). COVID-19 in older people: a rapid clinical review. Age Ageing, 49: 501-15.

[4] Soto-Perez-de-Celis, E. (2020). Social media, ageism, and older adults during the COVID-19 pandemic. EclinicalMedicine, 29-30, 100634.

[5] Hans Henri P. Kluge, (2020). Supporting older people during the COVID-19 pandemic is everyone's business. https://www.euro.who.int/en/health-topics/health-emergencies/coronavirus-covid19/news/news/2020/4/supporting-older-people-during-the-covid-19-pandemic-is-everyones-business (accessed 15.1.2020)

[6] Seifert, A and Hassler, (2020). Impact of the COVID-19 Pandemic on Loneliness Among Older Adults RIEF RESEARCH REPORT https://www.frontiersin.org/articles/10.3389/fsoc.2020.590935/full doi: $10.3389 /$ fsoc. 2020.590935

Funding: This short letter received no external funding.

Conflicts of Interest: The authors declares no conflict of interest.

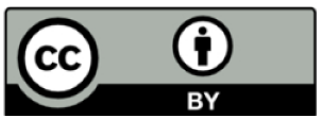

Copyright (C) 2021 by the authors. This is an open access article distributed under the Creative Commons Attribution License (https://creativecommons.org/licenses/by/4.0/), which permits unrestricted use, distribution, and reproduction in any medium, provided the original work is properly cited.

\section{About the Authors}

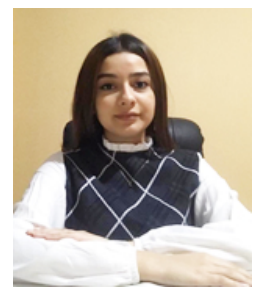

Lala Huseynova was admitted to the Faculty of Humanities at the University of Azerbaijan in 2017, majoring in "Social Work". Currently studying in the last year of undergraduate. 


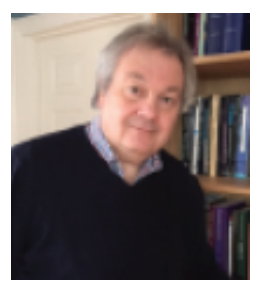

Dr. Paul Gibbs is Professor and Director of the Doctoral School, East European University. He is professor emeritus at Middlesex University, founder of the Centre for Education Research and Scholarship, and visiting professor at UTS Sydney and Azerbaijan university. His is a fellow of ATLAS as well as the Centre for Higher Education Policy, New College Oxford. He is an educator and researcher having taught notions of transdisciplinarity alongside social realism and Heideggerian hermeneutics. He has over 30 successful transdisciplinary professional doctorate students. He has published 20 books on topics ranging from the marketing of higher education to vocationalism and higher education and has published more than 100 academic articles. His particular approach to transdisciplinarity is informed by the works of Heidegger, Duns Scotus, and Deleuze and the theoretical insights of Basarab Nicolescu. He is also the series editor of SpringerBriefs on Key Thinkers in Education. 